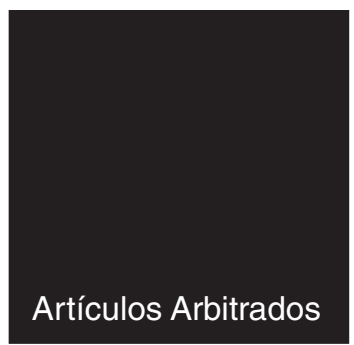

\title{
La ocupación silenciosa del espacio Conformación y crecimiento de las villas en la ciudad de Buenos Aires, 1930-1958
}

\section{Eva Camelli}

Doctora en Ciencias Sociales (UBA, 2014) y licenciada en Sociología (UBA, 2003). Becaria posdoctoral del CONICET. Docente del Seminario de Investigación sobre Historia Política de las Villas para la carrera de Historia, Facultad de Filosofía y Letras de la UBA. Miembro de Info Hábitat, Instituto del Conurbano, UNGS y del equipo de investigación "Cuestión social y hábitat: intervenciones públicas en villas y asentamientos en la RMBA", dirigido por María Cristina Cravino. Fue becaria doctoral de la Universidad de Buenos Aires. Su línea principal de investigación aborda los modos de producción política en las villas.

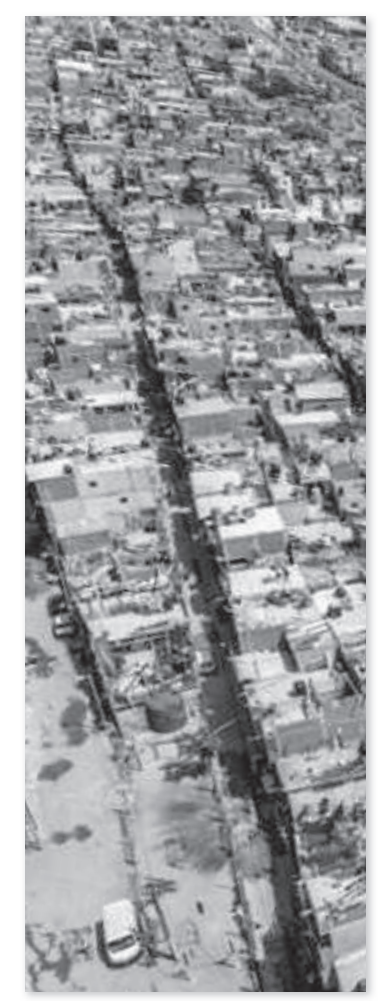




\section{Resumen}

El artículo busca reconstruir el origen de las villas en la ciudad de Buenos Aires y, a partir de esto, realizar un recorrido por la historia de estos espacios urbanos revisando dos aspectos centrales:

1. los modos que asumió el crecimiento de las villas y sus causas y

2. la organización territorial que se fue desarrollando en el transcurso de este crecimiento y los motivos que la impulsaron.

El trabajo contempla el período transcurrido entre la década de 1930, momento en que se origina esta forma de habitar la ciudad, y el año 1958, cuando se impulsa la primera organización política villera, situación que genera un quiebre en los modos organizativos que se venían desarrollando en el territorio.

\section{Palabras clave}

Villas; peronismo; organizaciones barriales; hábitat; política.

\section{Abstract}

The silent creation of habitats. Structure and growth of shanty towns in the city of buenos aires, 1930 - 1958

The article seeks to reconstruct the origin of the shanty towns in the city of Buenos Aires and, from there, analyse the history of these urban spaces, reviewing two central aspects: 1 - modes which the growth of the shanty towns took and their causes

2 - the territorial organization that was developed during this growth and the reasons that fostered it.

The study includes the period of time elapsed between the 1930 decade, the starting point of this way of inhabiting the city, and 1958, the beginning of the first slum dwellers political organizations, a situation that generated a breakdown in the organisational modes that were developing in the shanty towns.

\section{Keywords}

Shanty towns; peronism; neighborhood organizations; habitat; politics. 


\section{Introducción}

Este artículo busca desandar los orígenes de las villas en la ciudad de Buenos Aires. En este recorrido se aborda el tema en dos direcciones: en términos urbanos, rastreando y analizando el proceso de formación de las villas y, paralelamente, se indaga a las villas en términos políticos, observando cuándo se organizan territorialmente y las causas que explican dicha organización. Así, el objetivo es situar históricamente los orígenes y el desarrollo del fenómeno urbano conocido como villas miseria en Buenos Aires y, en ese contexto, problematizar los modos de organización que se fueron desarrollando en el territorio durante los años 1932, año de conformación de la primera villa porteña, y 1958, momento de conformación de la primera organización política en las villas.

\section{Surgimiento de las villas en la ciudad}

Si bien resulta difícil establecer un punto de partida exacto acerca de los inicios de esta particular forma de asentamientos urbanos, la bibliografía sobre el tema acuerda en marcar el año 1932 como hito fundacional de las villas de Capital Federal. ${ }^{1}$ En ese momento se culminó un tramo de obra del subterráneo, para la cual la empresa encargada había contratado a trabajadores de origen polaco que viajaron al país con ese proyecto. Culminada la labor, no lograron conseguir nuevo empleo y, en consecuencia, se encontraron sin opciones de vivienda. Para resolver el problema se asentaron en la zona de Puerto Nuevo (Palermo) y conformaron un campamento que se llamó villa Desocupación, en alusión a la crisis mundial de 1929. La villa fue erradicada y demolida en 1935 por orden del presidente de facto Agustín Pedro Justo. Los habitantes fueron trasladados a galpones ofrecidos por el Estado en la zona de Retiro, y los pobladores cambiaron el nombre del lugar bautizando a la nueva villa como villa Esperanza.

Paulatinamente, las villas en la Capital Federal se fueron incrementando y se ubicaron en las cercanías de diversas actividades laborales, situación que brindaba comodidad y abaratamiento en el transporte entre el hogar y el trabajo. Para los nuevos habitantes de la ciudad, la llegada a la villa fue percibida como un momento de transición, para lograr asentarse en la metrópoli y posteriormente arribar a una vivienda en la ciudad formal.
1. Si bien se encontraron indicios de existencia de viviendas precarias en tiempos anteriores en la zona del Bajo Belgrano y en Parque Patricios, conocida como el barrio de las Ranas, acá se retoma el consenso construido en la mayoría de los textos académicos. 


\section{Eva Camelli}

Las villas alcanzaron una mayor presencia en el tejido urbano durante la década de 1940, momento en que se profundizó el proceso de industrialización por la sustitución de importaciones, la cual demandaba fuerza laboral en los centros urbanos donde se radicó la industria. La descomposición de las economías regionales, junto con el crecimiento económico centrado en la industria ubicada en las grandes urbes, alentó el crecimiento demográfico concentrado en la gran ciudad. "Sin embargo, la tasa de crecimiento de la población urbana fue mayor a la del crecimiento de la población industrial, lo que provocó una masa de marginados del proceso productivo o de una inserción inestable" (CRAVINO, 2006: 36). Esta inserción inestable implicó el aumento de trabajadores informales y de subocupados que no lograron percibir los ingresos suficientes ni cumplir con las exigencias necesarias para acceder al mercado de vivienda de la ciudad formal. De esta manera, uno de los efectos de este proceso migratorio fue el empeoramiento de la situación habitacional en la ciudad. Para muchos de estos nuevos pobladores, corridos de sus pueblos y ciudades de origen por la falta de trabajo, les resultó imposible acceder a una vivienda en la ciudad formal, y permanecieron —en su gran mayoría — en las villas. Esta permanencia de sectores pobres en asentamientos por fuera de las normas legales de utilización del suelo irrumpía como un problema novedoso en la Capital Federal y en el país.

El modo en que las villas se fueron instalando y creciendo a lo largo de estos años mantuvo tres características constantes: la aspiración a realizar proyectos individuales, el modo pacífico de la instalación de las familias en los terrenos y la conformación de una traza urbana irregular, al tiempo que ilegal, situación que derivó en la conformación de la ciudad informal. Y las tres características se encuentran concatenadas: porque son proyectos individuales cada familia va tramando individualmente las estrategias posibles para arribar a la ciudad, las cuales estuvieron exentas de todo tipo de conflicto, y porque son proyectos individuales es que la trama urbana no cuenta con una organización preestablecida.

La llegada a la ciudad estaba cargada de expectativas de mejoramiento en la calidad de vida de cada una de las familias migrantes. Si bien puede resultar contradictorio contemplar la instalación de una vivienda precaria en una villa como una mejora en la calidad de vida, no hay que olvidar que las situaciones de las economías regionales en proceso de extinción hundían a las familias en una pobreza mucho más cruda que la vivida en la ciudad.

En este aspecto cabe destacar que uno de los alicientes principales de las familias migrantes era acceder a diversas oportunidades laborales y servicios urbanos. Retomando el trabajo 
de Oszlak (1991: 24), este define el derecho al espacio urbano "como un derecho al goce de las oportunidades sociales y económicas asociadas a la localización de la vivienda o actividad", y este derecho puede ser ejercido tanto por propietarios como por ocupantes ilegales de tierras. Así, el derecho al espacio conlleva diversas externalidades estrechamente ligadas a la localización de la vivienda o la infraestructura económica, tales como la educación, la recreación, la fuente de trabajo, la atención a la salud, el transporte o los servicios públicos. En la medida en que estos bienes y servicios tengan una distribución "geográfica" desigual, las posibilidades de acceso a ellos según lugar de residencia o actividad variarán correspondientemente (OszLaK, 1991: 24).

Dijimos que la motivación central en los procesos migratorios que tenían como destino la Capital Federal estaba asentada en las oportunidades laborales que ofrecía la metrópoli. Pero también existían motivaciones adyacentes, centradas principalmente en el acceso a bienes y servicios urbanos. Así, por ejemplo, el acceso al agua (por más que fuera a través de una canilla pública a varios metros de la casilla), la luz (por más que fuera adquirida mediante un cableado propio e informal), el acceso a educación y salud pública, etc., se constituyeron como factores también atrayentes para familias que carecían de dichos servicios en sus lugares de origen.

En términos muy generales, el proceso migratorio comenzaba con la llegada a la Capital Federal del jefe de familia, quien se hospedaba en un primer momento en la casa de algún familiar ya instalado en alguna villa de la ciudad. Luego de asentado, y con alguna certeza laboral en curso, comenzaba inmediatamente la instalación de la propia casilla en algún terreno aledaño ${ }^{2}$ y seguidamente la llegada del resto de la familia.

Una vez arribados a la Capital Federal, no existía una planificación previa acerca de los modos de organización de las viviendas en el territorio. Esto devino en una urbanización improvisada, lo cual se conformó como una de las características sobresalientes de las villas. La inexistencia de una traza urbana formal o "tradicional", con manzanas, calles y veredas definidas, hizo que estos fragmentos urbanos se conformaran sobre la base de un cúmulo de pasillos a través de los cuales se transita el barrio y se accede a las viviendas.

Un dato de relevancia en este proceso de conformación y crecimiento de las villas era la convicción sobre la transitoriedad de la residencia en estos lugares de las familias migran-
2. En los años que estamos analizando existía una amplia disponibilidad de terrenos vacantes en estas zonas en constante crecimiento. Esta situación es completamente diferente en la actualidad, cuando la saturación de los terrenos donde se asientan las villas impide la construcción de nuevas viviendas en lote particular. En consecuencia, desde hace ya varios años las villas de la ciudad de Buenos Aires se caracterizan por la construcción en altura y también por la existencia de un mercado inmobiliario informal, sistema a través del cual las familias acceden hoy a las villas porteñas. Para un análisis detallado de este tema véase MARÍA CRISTINa CRAVINo (2006). 


\section{Eva Camelli}

tes. La esperanza y las expectativas sobre el ascenso social que podía ofrecer un trabajo en la ciudad hacía pensar que el paso por la villa era solo el primer momento en el proceso migratorio. Como explica PASTRANA (1980: 129): las mejores condiciones objetivas de vida de los sectores populares durante el gobierno peronista tenían como consecuencia que los habitantes de estos asentamientos consideraran como algo transitorio el hecho de habitar viviendas en malas condiciones en terrenos ilegalmente ocupados, puesto que se percibían como parte de la clase trabajadora en continuo ascenso en su nivel de consumo.

Esta confianza en el paso transitorio por las villas convertía en un sinsentido cualquier tipo de planeamiento urbano a largo plazo. Si las viviendas en la villa eran el paso previo al acceso a un alquiler en la ciudad, ¿cabía la necesidad de planear colectivamente estrategias para optimizar el uso del espacio físico en beneficio de los habitantes? ¿Qué motivación puede movilizar a un grupo familiar a defender espacios de uso colectivo si cree que en poco tiempo ese espacio ya no le será propio? Esta expectativa de transitoriedad colaboró con la conformación un tanto anárquica que caracterizó a las villas porteñas en su proceso constitutivo.

\section{La construcción de la identidad villera}

Con los elementos distintivos en este período de conformación y crecimiento de las villas en Capital Federal, estamos en condiciones de establecer algunas características fundamentales. Si bien la formación data de los primeros años de la década de 1930, un crecimiento más acelerado se dio durante la década de 1940, período que se corresponde con el primer gobierno peronista, el cual acentuó el proceso de industrialización en el país. La confianza depositada en este gobierno por parte de los sectores populares conformó la idea de que la villa sería solo un lugar de tránsito, hasta comenzar el anhelado ascenso social. Esta característica hizo innecesaria la construcción de una identidad propia como sector específico dentro del entramado social, ya que se transitaba la vida en la villa como una situación provisoria, un mientras tanto, un entre: la villa era el paso obligado entre el lugar de origen y la aspirada vivienda de la ciudad formal. Es por eso que si bien durante la década de 1940 geográfica y poblacionalmente las villas crecieron, no lograron autodefinirse como un sector particular (villeros), como tampoco fueron catalogados como un grupo determinado por agentes externos. 
Específicamente el Estado no los definía con particularidad alguna, característica que excedió a la experiencia argentina. Reflexionando en torno al fenómeno en términos regionales, CRAVINo (2006: 26) afirma: "Una primera posición fue concordante con las posturas teóricas desarrollistas o funcionalistas, donde en los Estados latinoamericanos no se definieron acciones integrales respecto a los asentamientos informales, ya que se partía de la premisa según la cual el mismo proceso de crecimiento económico incorporaría a los pobres urbanos a la ciudad formal, tarde o temprano. La irregularidad urbana era entendida como un proceso transitorio, para el cual no era necesario desplegar intervenciones específicas”.

En nuestro país, la inexistencia de políticas públicas específicas para villas confirma esta tendencia: "el Estado realizaba planes — tanto de vivienda cuanto de promoción social- para el conjunto de la población de escasos recursos y no específicos para los habitantes de las villas" (Pastrana, 1980: 129). Concluye el autor: "el no ser considerados un grupo social con condiciones objetivas de vida, valores e intereses específicos, trae como consecuencia que no se organicen en su ámbito residencial. Muchos de sus integrantes, eso sí, pertenecían a organizaciones sindicales" (PASTRANA, 1980: 129). Como veremos en adelante, la no organización fue relativa, ya que, al menos incipientemente, contamos con datos que confirman ciertas experiencias de organización territorial.

Es posible pensar que, específicamente durante los dos primeros gobiernos peronistas, los residentes de las villas se hayan sentido representados y hayan construido su identidad en el interior del conjunto de los trabajadores peronistas sin necesidad de diferenciar su situación particular. En este sentido, propongo considerar a los villeros en este primer período como integrantes de una fuerza política a nivel nacional, concretamente la que gobernaba al país, y sin una identidad propia y diferenciada. Ambos procesos, la esperanza de transitoriedad y la adscripción al peronismo, inhabilitaron la construcción del sector villero como un grupo con especificidades diferenciadas. Al no constituirse como un sector específico, resulta imposible pensar en reivindicaciones propias como sector social, por más que las necesidades que los apremiaban eran novedosas en el contexto de emergencia de estos asentamientos urbanos. Los problemas vinculados con la particularidad villera se fueron resolviendo colectivamente pero sin una autodefinición concreta en cuanto a su situación como sector social. 


\section{Eva Camelli}

3. A principios del siglo XX la población comenzo un lento proceso de desconcentración poblacional causado por la venta de lotes en cuotas mensuales de terrenos en la zona suburbana y la puesta en marcha del tranvía eléctrico, que facilitó el traslado de la periferia al centro. Este proceso redujo la importancia del conventillo.

\section{Las políticas de vivienda durante los dos primeros gobiernos peronistas}

Teniendo en cuenta el apoyo brindado por los villeros al peronismo, cabe interrogarse acerca de las políticas destinadas a este sector. Concretamente: ¿qué hizo el gobierno peronista ante esta nueva situación planteada en el entramado urbano de la ciudad capital? Adelantamos recientemente la falta de políticas públicas destinadas a las villas, pero cabe revisar brevemente las características que adquirió la cuestión de la vivienda durante los dos primeros gobiernos peronistas.

Cuando Juan Domingo Perón arribó al poder, la vivienda ya era considerada un tema de gobierno. Se constituyó en una preocupación de las sociedades modernas, abordada en nuestro país desde finales del siglo XIX a causa del aumento de la demanda en vivienda y la saturación del mercado en las grandes ciudades, producido por la inmigración. El hacinamiento en espacios sin garantías sanitarias básicas fue el resultado de este fenómeno, analizado por higienistas, políticos e instituciones de beneficencia, que a través de la observación del hábitat popular construyeron a la vivienda como materia de crítica moral.

En Capital Federal, el conventillo fue la expresión habitacional del proceso inmigratorio. Se conformó paralelamente al modelo agroexportador, que comenzó a intensificarse para la década de 1880 y que determinó a la ciudad capital como el centro geográfico de concentración poblacional. Una parte importante de inmigrantes que no consiguió convertirse en propietaria rural se empleó en diversas actividades económicas de la ciudad, y demandó bienes y servicios, entre ellos, la vivienda. El conventillo como modo habitacional fue la respuesta a esta demanda de vivienda porteña. El proceso se inició con el abandono de las casonas de la zona sur del centro por parte de la clase alta (propietaria de aquellas) y la inmediata subdivisión y alquiler por cuarto de dichas casonas, lo que dio origen a este nuevo modo de hábitat popular caracterizado centralmente por el hacinamiento y la insalubridad. ${ }^{3}$

Para atender el tema habitacional, se creó en el año 1915 la Comisión Nacional de Casas Baratas, proyectada y defendida en el Congreso por el diputado Juan Félix Caffarata. Esta fue la primera intervención estatal sobre la vivienda de interés social, y dependía del Ministerio del Interior. La misión de la comisión "consistía en difundir y orientar en materia de 
habitar, aplicar exenciones impositivas a los emprendimientos que incorporaran ciertas normas de economía e higiene y realizar construcciones experimentales a las que se asignaba un carácter ejemplificador" (BALLENT, 2009: 56-57). La idea más importante resultante de aquella experiencia fue la defensa de la intervención del Estado en la construcción de viviendas y la expansión de su incidencia en el mercado, que desde sus inicios adquirió una concepción liberal en su funcionamiento.

De este modo, el período anterior a los gobiernos peronistas en materia de vivienda popular puede ser definido como un momento de debate en torno a los modos que debía adquirir el hábitat popular. Con el peronismo empezará una nueva etapa signada por el comienzo de obras concretas, que analizaremos en lo sucesivo, y por la continuación del debate iniciado en las décadas anteriores, el cual dejaba una gran cantidad de temas abiertos.

El gobierno de facto iniciado con el golpe de Estado el 4 de junio de 1943, del cual el general Juan Domingo Perón formaba parte, asumió una serie de medidas que beneficiarían a los sectores medios y medios bajos en relación con la vivienda, aunque no así a la población villera, que quedó al margen de las medidas planteadas. Prueba de ello fueron el control de precio de los alquileres ${ }^{4}$, la extensión de los beneficios de los créditos de la Ley de Casas Baratas a todo el territorio nacional (hasta el momento solo se habían realizado escasas obras en Buenos Aires) y la convocatoria a una Comisión Asesora de la Vivienda con el objetivo de elaborar un Plan Nacional de Vivienda Popular.

Con las elecciones presidenciales celebradas en febrero de 1946, Perón arribó a la presidencia del país. Los cambios institucionales enunciados se vieron reflejados en el plano jurídico, al plantear a la vivienda en términos de derecho. Así, el 24 de febrero de 1947 Perón proclamó los Derechos del Trabajador, que contenían como uno de los componentes del derecho de bienestar a la vivienda: "El derecho de los trabajadores al bienestar, cuya expresión mínima se concreta en la posibilidad de disponer de vivienda, indumentaria y alimentación adecuados, de satisfacer sin angustias sus necesidades y las de su familia en forma que les permita trabajar con satisfacción, descansar libres de preocupaciones y gozar desmesuradamente de expansiones espirituales y materiales, impone la necesidad social de elevar en nivel de vida y de trabajo con los recursos directos e indirectos que permita el desenvolvimiento económico" (La Nación Argentina, Justa Libre Soberana, 1950: 157-159).
4. Medida que contaba con un antecedente proveniente de un gobierno radical: en 1921 se aprobó la primera legislación tendiente a congelar los alquileres $y$ prohibir los desalojos en Capital Federal hasta el año 1925. 


\section{Eva Camelli}

Posteriormente, el derecho a la vivienda fue reconocido e incluido en el artículo 37 de la Constitución Nacional del año 1949, que proclamaba que "el derecho a un albergue higiénico, con un mínimo de comodidades hogareñas, es inherente a la condición humana” (BALLENT, 2009: 64). De esta manera, se iniciaba una nueva forma de concebir la vivienda: ligada directamente a un derecho que debía ser garantizado por el Estado demandando indefectiblemente su intervención en el mercado. Hasta acá las concepciones declarativas. En los hechos el tema se presentó mucho más complejo que lo estipulado en términos discursivos.

Durante el primer Plan Quinquenal (1946-1952), las instituciones a cargo de las obras fueron el Ministerio de Obras Públicas, la Municipalidad de Buenos Aires y el Banco Hipotecario. A diferencia de la política centralizadora acontecida en el período 1943 y 1946, estos años se caracterizaron por facultar a diferentes organismos la formulación de distintos planes de vivienda.

El Ministerio de Obras Públicas asumió una relevancia destacada al incrementar la producción directa a través de una nueva repartición, la Dirección de la Vivienda, creada en 1948 (la cual dependía de la Dirección Nacional de Arquitectura). Las acciones de este ministerio deben observarse en relación con las obras encaradas por la Fundación Eva Perón, que recurrió al organismo público para ejecutar un plan de 40.000 viviendas en el interior del país a través de la campaña "Ayuda Social Campaña María Eva Duarte de Perón”.

La Municipalidad de Buenos Aires, por su parte, creó la Dirección Municipal de la Vivienda e inició la construcción de 2700 viviendas entre 1946 y 1949. Pero los cambios de gestión en el municipio en el año 1949 llevaron a la disolución de la Dirección Municipal de la Vivienda y el abandono de cualquier tipo de política habitacional.

Mientras la municipalidad atravesaba una retracción en su protagonismo como ente ejecutor en materia de vivienda, el Banco Hipotecario recorría un camino inverso, a través de la expansión de créditos de fomento a la vivienda propia accesibles para los trabajadores con empleo estable, aunque, es de destacar, las acciones no se concentraron en Buenos Aires. Pero los cambios económicos causados por la reacción a la crisis de 1948-1949 impactaron en las políticas del banco, que restringió los créditos destinados a adquisición de vivienda y orientó su estrategia a los créditos destinados a la construcción de vivienda. 
El Segundo Plan Quinquenal (1953-1957) se caracterizó por un repliegue del Estado en materia de acción directa y un impulso a las actividades de fomento. En lo que respecta a la vivienda, se estimuló la acción de las asociaciones intermedias, especialmente las asociaciones profesionales, para la realización de viviendas para sus afiliados.

Dentro del período comprendido por los dos primeros gobiernos peronistas, podemos identificar un primer momento en que se reconoce a la vivienda como un derecho que debe ser garantizado por el Estado, y en el cual se avanza considerablemente en inversión estatal en materia de vivienda, específicamente entre los años 1946-1949 del Primer Plan Quinquenal, y un segundo momento caracterizado por el repliegue de las políticas públicas en materia de vivienda, que vulneró el derecho recientemente garantido.

Lo que se mantiene constante en ambos momentos es la ausencia de políticas destinadas específicamente al sector villero, situación que sí será abordada en los gobiernos sucesivos. Las acciones efectivamente realizadas por el peronismo fueron destinadas a obreros y empleados formales sin planificar un modo de abordar la problemática de la vivienda para la novedosa y creciente situación urbana plasmada en las villas. Es probable que el gobierno haya conjeturado que la propia dinámica redistributiva impulsada desde su política económica acomodaría a esas familias en lugares dignos de vivienda.

De todas maneras, si bien los villeros no fueron alcanzados por el derecho a la vivienda estipulado por el peronismo, la valoración de otras instancias de derechos sí conquistados y disfrutados hizo crear y mantener una identificación con el peronismo, aun encontrando el escollo de no poder emigrar de la villa como lugar de residencia.

\section{Las organizaciones barriales}

Durante los años que van desde 1932 a 1958, se crearon y desarrollaron en las villas organizaciones barriales, centralmente relacionadas con el deporte y el esparcimiento. La más importante estuvo vinculada con el fútbol: los equipos y campeonatos fueron una constante en estos años. Una investigación enmarcada en la historia oral realizada por el equipo del Instituto Histórico de la Ciudad de Buenos Aires sobre la villa 19 (ubicada en el barrio de 


\section{Eva Camelli}

5. Se trata de entrevistas realizadas por la autora para su investigación doctoral, titulada

"Politicidad villera, el Movimiento Villero Peronista, 1973-1976".

Facultad de Ciencias Sociales, Universidad de Buenos Aires, fecha de defensa: 4 de julio de

2014. villa Lugano) ilustra esta característica afirmando que durante la década de 1940 "la cancha de fútbol era el corazón del barrio; las casas crecían a su alrededor, los pasillos desembocaban en ella. Era el punto de reunión y encuentro" (Elba, entrevistada en CRONISTA MAYOR DE BUENOS Aires, 1999: 6), mientras José, otro entrevistado, relataba sobre los partidos que "iba toda la villa, el partido de los domingos, cuando llovía era un barrial. Hacían campeonatos y venían de todos lados, muchos equipos” (CRONISTA MAYOR De Buenos Aires, 1999: 6).

Asimismo, Ratier (1973: 87) destaca como otras actividades que propiciaron la organización interna de las villas a las tareas que demandaba el carnaval, con la organización de murgas y comparsas; la salud, ya que corría por cuenta de los vecinos la organización de atención médica alternativa, como los curanderos, referentes importantes de la salud para muchos de los migrantes. La religión también colaboró en la organización y articulación de los barrios.

Otro tipo de organización barrial de este primer período fueron los clubes de madres, que tenían por objetivo resolver los problemas vinculados con el cuidado de los hijos en el horario laboral de las madres. Todas estas prácticas contribuyeron a la integración de los vecinos, como así también a propiciar espacios de participación y organización.

Inmediatamente a estas experiencias surgieron organizaciones que buscaban dar respuestas a las condiciones del hábitat. "Los problemas de la villa son enormes y tocan aspectos fundamentales: falta de saneamiento ambiental, calles de tierra, a veces sin desagües, carencia de agua corriente y luz eléctrica, de protección médico sanitaria suficiente, etc." (RATIER, 1973: 89). En principio, los habitantes se organizaron para resolver por sus propios medios la obtención de recursos indispensables, como el agua, la luz y la apertura de caminos. Un entrevistado ${ }^{5}$ comentó que "Durante esos tiempos no había luz eléctrica en las casas. Había un sistema organizado por los vecinos que daban luz por horas... es que había toda una organización barrial para el alumbrado y el agua”.

Asimismo, en el trabajo citado sobre la villa 19, se encuentran estos relatos que abonan la misma idea: "vamos a organizarnos, dijimos, porque esto era todo barro y todo basural... Hicimos una salida para que pudiera tomar el colectivo la gente, si no te enterrabas hasta acá de barro" (Carballo, entrevistado en CRONISTA MAYOR DE BUENOS AIRES, 1999: 10); "necesitábamos agua y entonces se juntaron unos cuantos vecinos y pusieron la canilla, sabian por dónde 
pasaba el caño del agua y entonces compraron caños, pusieron plata y alargaron el tiraje, fue una cosa entre todos” (Bety, entrevistada en CRonista MAyor de Buenos Aires, 1999: 10). Relatos de habitantes de la villa 1-11-14 (Bajo Flores) suman información en esta dirección: "la gente siempre hacía cosas (...) había una comisión (...) mi marido fue presidente de la comisión del agua" (Licandra, entrevistada en CRONISTA MAYOR De Buenos Aires, 2002: 5); "primero se juntaba la plata para traer los caños (...) se ponía la fecha, un sábado o un domingo para trabajar (...) alguno que sabía más o menos de plomería lo hacía (...) entonces todos los vecinos que estaban anotados en el sector se ayudaban a trabajar y así se hizo el agua" (Beba, entrevistada en Cronista MaYor de Buenos Aires, 2002: 5).

A partir de estas primeras acciones colectivas nacieron organizaciones que se nuclearon en torno a las reivindicaciones relacionadas con su hábitat. Para llevar adelante estas demandas se conformaron Comisiones Vecinales o Juntas Vecinales; estas necesitaron un modo de organización más complejo que las organizaciones barriales de fines recreativos y deportivos. Según CRAvino (2006: 59), "las comisiones o juntas vecinales son formas de agrupamiento más complejas que las anteriores y exigen un cierto nivel previo de participación y organización de los vecinos. Las mejoras en la calidad de vida urbana y el rechazo al desalojo fueron los ejes principales del trabajo". De este modo, las carencias habitacionales fueron una motivación vital para la organización del barrio.

Por lo expuesto hasta acá, podemos afirmar que las organizaciones barriales atravesaron un recorrido donde los ejes de convocatoria y articulación grupal se fueron modificando: si en un principio la organización barrial se reunía en torno a cuestiones recreativas, sobre el final de este período el tema central que convocaba y movilizaba colectivamente a los villeros fue la problemática vinculada con el hábitat. Mientras las organizaciones recreativas fueron los exponentes de los primeros ensayos de organización barrial, las organizaciones vinculadas con demandas acerca del hábitat lograron arribar a incipientes acciones reivindicativas.

El trabajo realizado para mejorar el acceso a ciertos servicios fue atravesando diferentes etapas. El agua, como recurso vital, formula un buen ejemplo: comenzaron con la organización de horarios para cargar baldes fuera del barrio hasta lograr, con el trascurso del tiempo, la colocación de canillas públicas en las villas. El ejemplo de la villa 19 resulta ilustrativo: para obtener el agua la gente llevaba sus baldes y hacía largas colas durante el día 


\section{Eva Camelli}

y la noche. A fines de la década del 60 , los vecinos instalaron las primeras dos canillas colectivas en el barrio. Las dificultades con los caminos, el agua y la luz, y la necesidad de no resignarse (CRONISTA Mayor de Buenos Aires, 1999: 11).

La organización también fue necesaria para la instalación de la luz: "los días sábados y domingos los hombres traían palos, los postes para la luz o todo lo que se necesitaba (...) a veces las mujeres también sabíamos ir a traer (...) pero después siempre ellos organizaban grupos (...) Cuando nosotros vinimos a vivir a la villa no teníamos agua, nada, ni luz" (María, entrevistada en Cronista Mayor de Buenos Aires, 2002: 6).

Estas tareas instauraron nuevos espacios de sociabilidad en los cuales se fueron destacando líderes barriales, que ya tenían ganado un lugar especial entre los vecinos y tuvieron un rol importante en la gestación de las organizaciones. Muchos de los dirigentes de estos primeros años fueron obreros migrantes del interior del país que contaban con experiencia gremial y que capitalizaron esa práctica en la organización del barrio. De esta manera lo relataba un habitante histórico de la villa 19: "Las comisiones se conformaban en asambleas que se hacían en la cancha, había gente representativa, referentes, tipos que sabían manejarse a nivel municipal. Las reuniones de la comisión eran todas las semanas, había delegados por manzanas que se reunían una vez por mes” (José, entrevistado en CRONISTA MAYOR DE BUENOS AIRES, 1999: 12).

Los relatos de los habitantes de la villa 1-11-14 sobre las primeras comisiones vecinales expresan: "Había como un delegado, un representante por manzana o por pasillo y se juntaban los viernes, los sábados o cuando había problemas que se cortaba la luz, ya se buscaba a uno de la manzana; se reunían para ver el problema y de ahí salía uno o dos representantes y ya iban a la comisaría, a Segba, o el problema del agua, o lo que fuera (...) Así se fueron haciendo los pilares de la luz, (...) prolongación de los caños de agua" (Yolanda, entrevistada en CRONISTA Mayor de Buenos Aires, 2002: 5).

Los habitantes de las villas con práctica gremial aportaron su experiencia política para la conformación de este actor político en emergencia: el sector villero. Esta vinculación fundante entre militancia gremial y organización territorial será una constante, ya que los villeros entendieron que su calidad de trabajadores los legitimaba en la demanda de derechos referidos a la clase obrera. Tal como explica SNITcofsky (2011: 57): "la transmisión oral de la 
experiencia puede establecerse no solamente de manera diacrónica, a través de las sucesivas generaciones sino también, de un modo sincrónico, del ámbito del trabajo al vecindario. Así fue, por ejemplo, como las prácticas de negociación y resistencia adquiridas en ámbitos laborales, se reprodujeron en las villas para hacer frente a las amenazas de desalojo y resolver los problemas cotidianos. En estas situaciones, los referentes naturales fueron los vecinos con experiencia sindical previa; quienes sabían cómo capitalizar el esfuerzo colectivo para poner fin a los abusos y conseguir las mejoras en los barrios".

Alcanzada esta descripción histórica en cuanto a las primeras experiencias organizativas en las villas, me interesa plantear para el análisis la mirada de Denis MerkLen (2010) en torno a la politicidad de las clases populares. La propuesta analítica permite atender a tres características de los modos políticos de esta clase social. El primero de los aspectos que retomamos de la idea de politicidad popular se centra en entender a la política como práctica constitutiva de la vida social: "el concepto de politicidad se erige contra la visión teórica que busca aislar lo político de las otras esferas de la vida social (...) Las formas que adquieren las prácticas políticas de un grupo social cualquiera se encuentran íntimamente ligadas a los avatares de su condición social. Politicidad y sociabilidad marchan juntas. (...) Ese entramado de lazos políticos que capta el concepto de politicidad no puede ser definido: necesita ser descripto en cada coyuntura, en cada lugar, para cada grupo social. Es en el conflicto que se lo define” (MERKLEN, 2010: 19).

El otro aspecto para retomar invita a pensar específicamente a los sectores populares conformados por una dimensión meramente política: "cuando en el seno del análisis político se piensa en las clases populares, suele pensarse en el modo en que éstas 'acceden a la política' o 'entran en contacto con la política'. (...) La idea de politicidad popular permitiría en cambio estudiar el mundo popular con una dimensión directamente política” (MERKLEN, 2010: 19).

Este modo de abordar la práctica política tiene la virtud de no limitarse a observar solamente la actividad dentro de estructuras partidarias y, fundamentalmente, permite aprehender el dinamismo propio de la construcción colectiva. Las organizaciones barriales fueron las primeras experiencias de prácticas colectivas en las villas, y en ellas podemos identificar la génesis de una práctica política constituida en torno al territorio. De este modo, logramos identificar a la política como una actividad fundante y constitutiva en sociabilidad villera. 


\section{Reflexiones finales}

Retomando las ideas vertidas en el escrito, podemos afirmar que para comprender el origen de las villas y su posterior consolidación, es necesario vincular el fenómeno con el contexto económico nacional, dirigido por el modelo de industrialización por sustitución de importaciones. Los pobladores de estos años fueron migrantes de zonas no industriales del país, como así también inmigrantes de países limítrofes que arribaban a la ciudad motivados, centralmente, por mejorar sus condiciones laborales y también por mejorar su calidad de vida al acercarse a servicios urbanos no presentes en sus regiones de origen. El problema de este proceso se presentó cuando la masa migrante superó la capacidad industrial en la incorporación de recursos humanos, y el resultado fue un grupo de trabajadores que se empleó informalmente, no accedió al mercado de vivienda formal y acrecentó la población villera.

Asimismo, este momento asumió como sello distintivo tres características fundamentales: la realización de múltiples proyectos individuales, en los cuales el paso por la villa se contemplaba como transitorio; la ocupación silenciosa del espacio, debido a la serenidad en la disposición del suelo, y la conformación de una trama de ciudad informal instaurando un fragmento urbano sin estatus de ciudad.

La convicción depositada en la transitoriedad estaba vinculada con las expectativas generadas por el peronismo a las clases populares en general. Esta combinación devino en que los pobladores atravesaran todo este período sin poder establecer una identidad propia en el entramado social. Así, en los años que van entre 1932 y fines de la década de 1950 se destacan dos características: en términos urbanos, se conforman y consolidan las villas como espacios constantes en la ciudad y, en términos organizativos, se crean formas de organización barrial a través de agrupaciones relativas al esparcimiento, en principio, y luego agrupaciones reivindicativas de temas relacionados con el hábitat.

La mirada teórica presentada por MERKLEN acerca de la politicidad popular puede ser especialmente aplicada a la práctica política en las villas, sector perteneciente al campo popular. De este modo, propongo acotar el terreno y pensar las características que adquiere la politicidad específicamente de un sector en el interior de las clases populares: los villeros. Teniendo en cuenta la experiencia relatada en torno a las organizaciones barriales, ¿pode- 
mos comenzar a pensar en la existencia de un modo de practicar política propia, específica y característica de estos espacios urbanos? Por lo visto hasta acá, podemos reconocer una primera especificidad: en los años que componen el período de conformación y crecimiento de las villas de la ciudad, en ningún otro espacio urbano fue necesaria la organización territorial para resolver cuestiones inmediatas y vitales, como las reivindicaciones acerca del hábitat que quedaron expuestas. Los barrios de sectores pobres pueden llegar a tener estructuras urbanas que a veces resultan parecidas a las villas, pero la falta de servicios urbanos es un factor que los distancia. Excusados en la ilegalidad en relación con la tenencia de la tierra, los organismos públicos castigaron a estas poblaciones con la falta de servicios urbanos básicos, y la lucha por su obtención exigió una organización colectiva basada en la urgencia y una necesidad de solidaridad mutua incomparable.

Al permanecer en lo que en un primer momento se creyó transitorio, los pobladores de las villas necesitaron enfrentar una urgencia inaplazable: demandar las mejoras en las condiciones de hábitat, y para ello se necesitó comenzar a imaginar un horizonte de lucha común, un proyecto colectivo. Es posible reconocer cuestiones inéditas de organización política experimentadas en las villas, y propongo denominar politicidad villera a las características que fue adquiriendo la sociabilidad política dentro de esta población. 


\section{Bibliografía}

BALLENT, Anahí (2009) Las huellas de la política. Vivienda, ciudad, peronismo en Buenos Aires, 1943- 1955. UNQUI-Prometeo, Buenos Aires.

CRAVINO, María Cristina (2006) Las villas de la ciudad. Mercado e informalidad urbana. UNGS, Buenos Aires.

CRONISTA MAYOR DE BUENOS AIRES (1999). "En INTA la historia la escribimos entre todos. Primera parte: la historia del barrio INTA- Villa 19- desde sus orígenes hasta el año 1976”. Año 2, N. 9 (pp. 1-16). Instituto Histórico de la Ciudad de Buenos Aires, Buenos Aires. (2002). "Villa 1-11-14. Cincuenta años de historia (primera parte)”. Año 4, N. 33 (pp. 1-8). Instituto Histórico de la Ciudad de Buenos Aires, Buenos Aires.

LA NACIÓN ARGENTINA, JUSTA LIBRE SOBERANA (1950). Disponible en: http://www.ruinasdigitales.com/revistas/PatriaJustaSoberana.pdf (consulta: julio de 2016).

MERKLEN, Denis (2010) Pobres ciudadanos. Las clases populares en la era democrática (Argentina, 1983-2003). Gorla, Buenos Aires.

OSZLAK, Oscar (1991) Merecer la ciudad. Los pobres y el derecho al espacio urbano. Humanitas-CEDES, Buenos Aires.

PASTRANA, Ernesto (1980). "Historia de una villa miseria de la Ciudad de Buenos Aires (1948- 1973)”. En: Revista Interamericana de Planificación, volumen XIV, N. ${ }^{\circ}$ 54, 1980 (pp. 124-140).

RATIER, Hugo (1973) Villeros y villas miseria. CEAL, Buenos Aires.

SNITCOFSKY, Valeria (2011). "Villas de Buenos Aires y conflictos portuarios bajo el gobierno de Onganía: aportes para un análisis de la articulación entre sindicalismo de base y organización territorial”. En: Basualdo, Victoria (coord.) La clase trabajadora argentina en el siglo XX: experiencias de lucha y organización (pp. 51-80). Atuel, Buenos Aires. 